\title{
Role of Small Businesses in the Agricultural Sector of the Region
}

Panasyuk M.V.

\author{
Safiullin L.N.
}

Gafurov I.R.

Safin A.R.

\author{
Kazan Federal University, Institute of Management, Economics and Finance, Kazan, 420008, Russia \\ Email address: mp3719@yandex.ruu
}

\section{Doi:10.5901/mjss.2014.v5n28p56}

\begin{abstract}
The article considers the agro-industrial sector, which represents a major sector of the national economy and plays an important role in regional economics of the Republic of Tatarstan. The development of small entrepreneurship in the agroindustrial complex forms the potential sustainability of the region's economics, especially in times of economic crises
\end{abstract}

Keywords: regional economics, small business, agribusiness, effectiveness of small business.

\section{Introduction}

Improving the efficiency of small and medium-sized enterprises in the industrial sectors is a multidimensional problem, the solution of which depends on a complex combination of economic, social and institutional factors $[10,11]$. The current state of play in Russian small business in agro-industrial complex (AIC), including its relatively low technical and technological level, inadequate organizational culture, social problems of rural communities, etc. forms objective obstacles to the growth of its efficiency. The weakening of these adverse conditions is impossible without state support and state regulation of small business development, which is largely determined by the specifics of agricultural production and consequent peculiarities of agricultural economics.

In recent years, Russia has largely managed to overcome the stagnation in development of small business in agriculture due to increased attention to its problems from the government. However, the measures taken are far insufficient, largely due to the imperfection of the current legislation, the imperfection of tax policy in agriculture, the challenges of lending to agricultural enterprises, incomplete information support for small agribusinesses and others. There is no developed mechanism of state regulation of small and medium-sized agro-industrial enterprises, weak innovation mechanism and marketing system, etc. [1, 4].

The main factors of formation and development of agro-industrial branches, and combination of these factors are specific to each region. The level of its socio-economic development directly effects on the development of all sectors of the regional agro-industrial complex, mainly due to the level of development of production and social infrastructure. Structure, specialization and production of branches of regional agro-industrial complex is largely determined by the predominant influence of natural conditions and resources, peculiarities of structure of land fund, the specifics of the settlement system and others [2]. The influence of natural-economic zones factor, the zonal nature of organization of agricultural production in the region is offset by the impact of large cities or urban agglomerations.

\section{Features of Economics of Agro-Industrial Complex of the Republic of Tatarstan}

The Republic of Tatarstan is situated in the Center of Russia at the junction of its European and Asian parts, and of forest and steppe zones, at the confluence of two large rivers - Volga and Kama, has favorable economic and geographical position, and significant economic and natural potential. The terrain and the large extent of the region in the meridional direction define the diversity of soils and vegetation. Land resources of the Republic of Tatarstan is equal to 6783,7 thousand hectares, including agricultural lands - 4.5 million hectares, 3.5 million hectares of which is arable land. The main part of land resources is occupied by agricultural land (70\%), then forest (18\%) and water (7\%). The population of 
the Republic of Tatarstan is 3.84 million (2014), that forms the basis for creating large regional market of agricultural products. The population living in rural areas is 943,5 thousand people.

In the structure of regional agricultural production branches of livestock industry and crop production (primarily grain farming) are represented. Grain area is located about from the latitude of Kazan to the latitude of Samara (where rye, winter wheat are cultivated). Industrial crops are widespread, for example mustard crops account for $90 \%$ of the crop of this culture in Russia.

The region has significant potential for livestock industry development. Having a high density of livestock and poultry husbandry, the Republic is increasing its contribution to the food security of the country. In all categories of farms there are over 1 million heads, including more than 400 thousand head of cattle, more than 700 thousand pigs, 13.1 million poultry [8]

In the agricultural sector of the Tatarstan the diversified multi-structured economics has formed. Large strategic investors and private companies control agricultural production on the basis of half of the arable land and livestock of the region using the most modern technology of production. They invested more than 90 billion rubles in agribusiness development. Major investors are "VAMIN Tatarstan", JSC HC "Golden Spike", JSC "Agrosila Group", OJSC "Krasny Vostok-Agro", JSC HC "AK Bars-Agro".

The agricultural sector plays an important role in the economics of the Republic of Tatarstan. Development of agroindustrial complex has been and remains one of the priorities of economic policy of the regional administration, its branches has significant public support. Since 2000, despite crisis phenomena in the regional economics, relatively stable growth of livestock industry and crop production is maintaining. The Republic is one of the three leaders among Russian regions by the volume of gross agricultural product and fully meets the needs of the regional population in basic foodstuff.

The main purpose of AIC of the Republic of Tatarstan, as it was formulated in its Strategy of socio-economic development for the period till 2030 [8], is a stable food supply primarily by livestock products, for not only the population of the Tatarstan, but also for many regions of the Russia, taking into account saved labor potential in rural areas of the Republic, specific natural conditions, and the accumulated investments.

The specificity of the Tatarstan in current economic environment is determined by high level of financial and organizational support for agro-industrial complex, the responsible attitude of the regional authorities to agriculture, the increased role of large modernized agricultural holdings, multinational composition of the rural population.

The Republic of Tatarstan, unlike many of the more urbanized regions of the Russia, entered into the difficult transition period with retained countryside and rural mentality of significant (up to a quarter) part of its inhabitants. The rural population has participated actively in numerous economic and social programs of development of agricultural production, which have been developed in recent years by the Government of the Republic, including, for example, social mortgage for public sector employees, programs of schools, kindergartens, and clubs repair, programs of medical and obstetric centers construction, programs of sports complexes construction in rural areas etc.

The main threats of reduction and deterioration of human capital emerging in the near future in rural areas, however, will continue to grow. Among them are continued migration of rural population to the cities, the growth of regional and municipal centers at the expense of rural areas and the "loss" of active social life of small rural settlements, outflow of rural youth in large cities, and especially in Kazan as the regional capital, for higher education (mainly nonrecoverable). Under these conditions, small agricultural enterprises form the socio-economic conditions for solving these above problems of development of the region, creating, first of all, the conditions for improving the quality of life of rural population.

According to various estimates the number of rural population in the region could be reduced by $15-30 \%$ by 2030 . Serious challenges to sustainable development in the region will be the problems of reducing the number of villages where necessary to preserve and maintain expensive social infrastructure, the problems of kindergartens and schools usage in situation of decreasing fertility in rural areas, the problems of maintain of the culture of minority ethnic groups living in rural areas, the fall in prestige of agricultural labor, changing of ethnic composition of the population (tributary of population in the countryside recent years comes from the nearest countries), the problems of insufficient infrastructure construction and network services in rural areas [8].

\section{The Role of Large Agro-Industrial Enterprises in the Economics of the Region}

The feature of the modern economics of AIC in the Republic of Tatarstan is an increased role of large enterprises in the agricultural production which is associated not with the decline of private households and poor farming as in most nonchernozemic regions of the Russian Federation, but with the concentration of production at the giant agro-industrial complexes. The agricultural holdings, due to stimulating policy of the Tatarstan Government, has become the main 
backbone part of the agroindustrial complex of the Tatarstan, which allowed in contrast to other regions of Russia to brake the decline of cattle and decrease in acreage in the early 2000s. In the majority of the municipalities they produce from 50 to $80 \%$ of agricultural products.

The course of the Government of the Republic of Tatarstan on the creation of mega-farms and large agricultural holdings had certain advantages, especially in the early stages and with substantial support from the regional authorities, and certain disadvantages. This has led to the destruction of mid-level independent agricultural enterprises in many municipal areas (raions). Initially aimed at the salvation of loss-making enterprises, the agricultural holdings began to "pick up" those that could survive by themselves, especially if they received sufficient support from the government.

Stimulation of large agricultural enterprises has led to the emergence of "strong overinflation" problems of these companies by borrowed funds, largely due to strong administrative and financial support of regional authorities.

«Overlending» of the largest agricultural holdings is largely determined by subjective reasons, by the discrepancy between the "appetites" of their owners and real opportunities for these enterprises and the Republic. An uncertainty of further budget opportunities of the Tatarstan for supporting agro-industrial complexes of the region, huge debts of agricultural holdings, the underdevelopment of market mechanisms of functioning of their units largely generate stubs for development of not only big, but small agribusinesses.

This leads to the fact that in the last 2-3 years negative trends in the development of regional agricultural industries was observed, including general slowdown in development, and due to the debts of large and mega-enterprises, lower profitability, lower efficiency of some of the large agricultural holdings, the loss of production at a number of enterprises, reduction of wages and failure to pay, and dismissal.

Serious threats in these conditions become reducing the competitiveness of the agricultural sector of the Tatarstan in the current market environment, the inability to pay the loans of, and dependence on the banks of the Russian Federation, the possibility of bankruptcy of some strategic enterprises, loss of livestock and abandonment of land, laying off workers and unemployment growth in rural areas, the strengthening of extremist behavior. Experience of other regions shows that public agricultural holdings as a rule are low-profit. The most effective companies are parts in the agricultural holdings with foreign parent companies (their cost effectiveness is two times above the average) [8].

The main advantage of the Tatarstan in the solution of the listed problems are regional initiatives and programs to support agriculture, including small and medium-sized enterprises. The rural population of the republic actively responded to stimulation of livestock farms. However, the problem is the lack of an extensive system of product marketing of small farms (not necessarily stationary, with large investments, but with an optimal arrangement of parts of the system). Many agro-industrial complexes are not engaged in processing of produced raw materials, just sell it to enterprises of other regions, thus the region does not receive additional revenue from the value added. This is important not only for the development of private livestock and crop production, but also for maintaining the population in rural areas.

Nationwide conditions for agro-industrial complexes development in the coming years should improve, but in their frameworks substantial co-financing of agro-industrial complexes from regional budgets is expected. This circumstances increase the burden on the budget of the Tatarstan in order to support its agricultural sector.

Under these conditions, the regulation of the optimal combination of agricultural enterprises of different sizes combined with an attempt to maintain large holdings and separation of their business units to independent companies is a difficult task, because you may lose those benefits that have large modernized enterprises. However, recovery at least a part of a number of lost small and medium-sized enterprises in the region will help to increase the overall efficiency of agro-industrial complexes.

\section{Prospects of Development of Small and Medium-Sized Agribusiness in the Republic of Tatarstan}

Research has shown that entrepreneurial potential of small and medium businesses is not enough used in the economic development of the region [5]. The number of small businesses are not growing, because main problems hindering the creation of new and development of existing enterprises are solved slowly. Therefore the development of small entrepreneurship in agro-industrial complexes is relevant for the Republic of Tatarstan and determines the necessity of the state support at different levels of management [6].

Currently, there is no doubt [7] that small businesses which do not require large initial investments and ensuring high turnover rate of resources, are able to solve most quickly and economically the problems of economic restructuring, formation and saturation of consumer goods market in conditions of limited financial resources. The degree of activation of small business largely depends on the political, economic and social stability of the region.

Small companies in regional agro-industrial complexes contribute to saturation of consumer food markets, increasing competition, job creation, rural development, preservation of folk arts and crafts, strengthening the economic 
base of regional and local authorities, social development of villages and improving the economic efficiency of agricultural production.

To improve the efficiency of the regional economics it is necessary to contribute to increase in the number of small businesses in agro-industrial complexes, to promote interrelations between small, large and medium business, because the business in general, regardless of size is indivisible and interconnected process [3].

Developing comprehensive support measures, regional authorities and management must take into account current social situation in small business, the interests of employees, the degree of their commitment to market relations, the nature of expected changes and prospects. Only in this case, the state support of small business will be effective and will contribute to its further growth and development in the interests of economics of the whole country.

The main and necessary condition for the formation and dynamic evolution of a system of small entrepreneurship in the agro-industrial sector is well-developed system of normative legal acts and the steady improvement of economic legislation, which create the basis of comprehensive and stable state support of small entrepreneurship in the period of its establishment.

In this regard it should be noted the emerging trend of national economic policy in Russia at all levels of government to strengthen the political influence of small entrepreneurship in order to strengthen its position. A new approach to the legal definition of small business, reflecting the current realities in the structure and European practice of small businesses division is elaborated. Thus small and medium business will be legally treated as a single sector[9].

Economic importance of small businesses for the development of agro-industrial complex of the Republic of Tatarstan is in increasing the efficient use of local sources of raw materials, saturation of the consumer markets for green products, providing deeper processing of secondary raw materials, introduction of new technologies, improving maintenance and repair of agricultural machinery, etc., that objectively contributes to revenue growth and profitability of the agriculture sector, and growth of the Gross Regional Product.

\section{Conclusion}

The analysis shows deeper processing of agricultural products and a significant increase in the value added, increase in volume of gross regional product in the development of the system of small and medium-sized agricultural businesses in the region. The result is also the increasing tax revenues to regional and local budgets, which contributes to strengthening the economic base of regional and local authorities. At the same time small business in the regional agroindustrial complexes contributes to the improvement of the parameters of social development of villages and the equalization of living standards in urban and rural communities. Its participation in creation of favorable conditions for employment of the rural population, reducing youth unemployment is especially important in conditions of crisis phenomena in the regional economics.

\section{References}

Kashaeva I. P., Murzin E. A. (2014) Ways of increasing the profitability of agricultural enterprises, Journal of Magistrate,4-2 (31), 140143.

Usachev I. (2008) Food security is the basis of stable development of the Russian economy, AIC: Economics, management, 8.

Aleke B, Ojiako U, Wainwright D. (2011) Social networks among small agribusinesses in Nigeria, Society and Business Review, 6(3), 214.

Fletcher C. (2014) Regional commission conference focuses on shared needs of small businesses, agribusinesses, McClatchy Tribune Business News, 2014.

Keeton K. Underestimating agribusiness? The Lane Report [Internet], 2013 [cited 2014 Jan 12], 28(8):38.

Russian agribusiness report - Q3 2014, Russia Agribusiness Report, 2014:1.

Sustainable agribusiness. Caribbean Update, 2013; 29(9):12.

The strategy for socio-economic development of the Republic of Tatarstan for the period up to 2030 See http://tatarstan2030.ru/ content96Small business: problems and prospects. See www.nisse.ru/ business/

Vecchi, V., Brusoni, M., Borgonovi, E. (2014) Public Authorities for Entrepreneurship: A management approach to execute competitiveness policies Public Management Review, 16 (2), 256-273.

Foreman-Peck, J. (2013) Effectiveness and efficiency of SME innovation policy, Small Business Economics, 41 (1), 55-70.

Razumovskaya, E.M.,Mishakin, T.S., Popov, M.L., Kucevol, N.G. Medical services during the XXVII world summer universiade 2013 in Kazan. Mediterranean Journal of Social Sciences vol. 5 (18 SPEC. ISSUE), pp. 17-20

Arustamyan, G.,Yegorov, E., Lipsky, S.,Razumovskaya, E.,Gimranova, L. Clinical and economic analysis and its role in healthcare quality management. World Applied Sciences Journal vol. 27 (3), pp. 318-323.

Derevenskaia Olga. Active learning methods in environmental education of students. Procedia - Social and Behavioral Sciences Vol. 131, pp. 101-104 // 3rd World conference on educational technology researches Turkey 07-09.11.2013. 